\title{
LA ENFERMERÍA Y LA REFORMA PSIQUIÁTRICO-PENITENCIARIA
}

\author{
Luis Fernando Barrios Flores* \\ *Área de Derecho Administrativo de la Universidad de Alicante
}

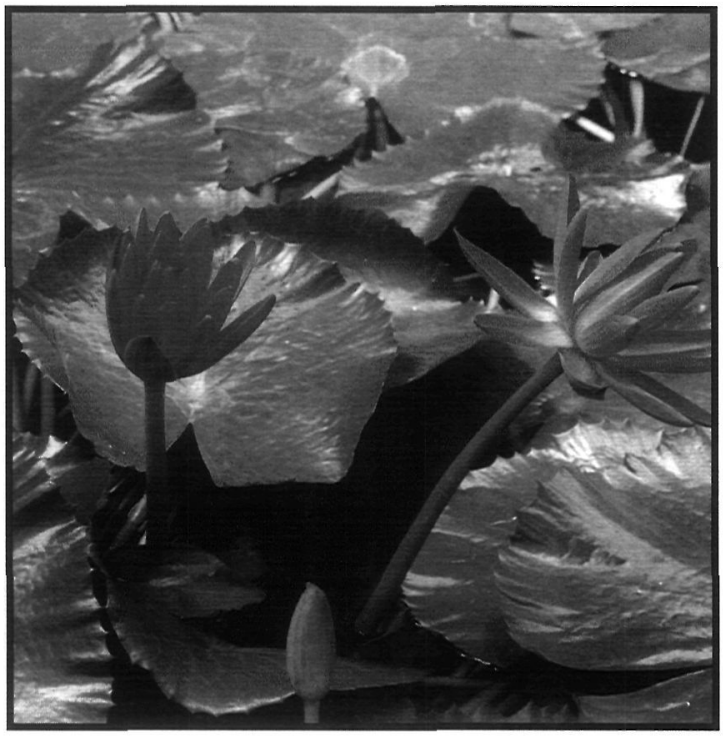

\section{ABSTRACT}

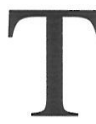

The origins of nursing professional practice are closely related to the reform process that took place during the historical period of Illustration. The culture of nursing care has traditionally had a remarkable presence in penitentiary and psychiatric areas. The historical shaping of both institutions - mental hospitals and prisons has occurred simultaneously.

For this reason, the most relevant historical facts of the so-called "humanity establishments" are described in this article. This term was used in the late XVIII c. To designate mental institutions and prisons. The most outstanding figures of moderns professional nursing were present then.

The specialization of establishments along with own professional moulding were demanded by time. During the XIX century, work and duties within penitentiary and psychiatric establishments acquired their own identity, and so did the nursing profession.

\section{RESUMEN}

$\mathrm{L}$ os orígenes de la práctica profesional en enfermería guardan una directa vinculación con todo un proceso de reforma situado en un período histórico determinado, la Ilustración. La cultura de los cuidados enfermeros ha tenido tradicionalmente una presencia de relieve en los ámbitos penitenciario y psiquiátrico. Y la configuración histórica de ambas instituciones -la manicomial y la carcelaria- han venido en gran parte de la mano.

Por ello se describen en este artículo las claves históricas más características de los llamados "establecimientos de humanidad". Con este nombre se englobaban a finales del XVIII cárceles y manicomios. La presencia de las figuras más señeras de la formulación profesional de la enfermería moderna es detectable en estos ámbitos.

El devenir histórico demandará una especialización en los establecimientos y una configuración propia de cada profesión. El siglo XIX será el período en el que las funciones y oficios de los establecimientos psiquiátricos y penitenciarios adquirirán perfiles propios. Otro tanto sucederá con la profesión enfermera.

\section{1.- LA ILUSTRACIÓN: \\ CIENTIFICISMO Y HUMANITARISMO.}

La Ilustración (Hirschberger, 1976) es un período de la historia del pensamiento que, abarcando todo el siglo XVIII (el llamado siglo de las luces" y de ahí también el uso del término iluminismo"), tiene orígenes en el XVII y extiende sus efectos en el XIX. Sus orígenes se residencian en Inglaterra, de ahí se extenderá a Francia y luego a Alemania e Italia, alcanzando más tardíamente a España en donde se asentará con caracteres propios.

Este movimiento, en los aspectos que aquí interesan, se caracteriza por una incuestionable fe en el 
progreso, es decir, como afirmara Inmanuel Kant en 1783 , supone la salida del ser humano de su minoría de edad, de la cual él mismo es culpable" (Kant, 1990); y, al mismo tiempo supone un individualismo humanitario" lo que comporta una creencia en que los problemas de los individuos y de las sociedades podrían resolverse si las fuerzas de la inteligencia y la virtud prevalecían sobre la ignorancia y la maldad" (Berlin, 1998). En ambos planos se comparten presupuestos inequívocamente racionalistas. De toda esta corriente de pensamiento somos en gran parte tributarios y la doctrina más solvente no deja de recordádnoslo (Foucault, 1999).

Será en este dilatado momento histórico en el que se sienten las bases de la reforma en los ámbitos sanitario y penitenciario, y más en concreto en lo que aquí va a ser objeto de nuestra atención, en los campos manicomial y carcelario. No obstante lo cual, es justo reconocer que en algunos lugares y particularmente en España- este movimiento ya contaba con una cierta tradición, pues en el caso del cuidado del enfermo mental el precedente de la obra del Padre Jofré (1409) es de obligada cita (Merenciano, 1950), y no solo porque tal experiencia se erija en un remoto antecedente histórico sino porque dicha tradición, en buena medida perduraría a través del tiempo. En concreto la práctica asistencial del Manicomio de Zaragoza merece el reconocimiento de la doctrina (Royo, 1935-1936) e incluso influiría de forma notable en líderes de la reforma psiquiátrica tan acreditados como el propio Pinel (Espinosa, 1964). Aunque un conjunto de factores (desamortización, pérdida de las colonias, crisis económica postbélica...) arruinarían tal tradición (Carasa, 1988; Comelles, 1988).

Por tanto, humanitarismo ya desde sus comienzos, y cientificismo, en la medida en que el avance del conocimiento lo hacía posible, se erigirán en los pilares básicos de la reforma psiquiátrico penitenciaria.

Analicemos pues, los frentes de una reforma ilustrada que en el caso que nos ocupa abarca desde una reforma penal intelectualmente presentada por Beccaria aunque respaldada por un auténtico clamor popular, hasta sus materializaciones penitenciaria y psiquiátrica. Podremos entonces constatar la presencia de la cultura de los cuidados en estos ámbitos. Presencia que no casualmente aparece con un carácter coetáneamente recurrente en manicomios y prisiones. Y es que el interés por los llamados establecimientos de humanidad" era lugar común (Hospitales y cárceles son dos grandes temas de discusión en los salones parisinos, en los círculos ilustrados") (Foucault, 1979).

\section{2.- LA REFORMA PENAL.}

El trato jurídico-penal al delincuente fue objeto de estudio de una obra que ha llegado a calificarse como _germen verdadero de nuestro derecho penal" (Bernaldo de Quirós, 1908). Dei delitti e delle poene (1764) de Cesare Beccaria (17381794) es, según el juicio crítico del siempre recordado Francisco Tomás y Valiente (Tomás y Valiente, 1974), un ataque demoledor al derecho penal de la monarquía absoluta abogando por: la racionalidad jurídica, la primacía del principio de legalidad, la publicidad procesal, la igualdad ante la ley, la proporcionalidad entre delitos y penas, la correlación entre penas y daño social producido, la eliminación de la crueldad, la búsqueda de un elemento más preventivo que retributivo...

La obra de Beccaria irradia sus efectos por toda Europa, correspondiendo en España a Manuel de Lardizábal y Uribe (1739-1820) representar el papel de heraldo de este pensamiento. Pero con un añadido, Lardizábal expresamente señala la inadecuación de la pena de prisión para los enfermos mentales, y ello aunque su enfermedad fuera sobrevenida (Lardizábal, 1782).

En lo que a los enfermos mentales respecta lo cierto es que desde antiguo, en teoría, su propio estado impedía la imposición de medidas penales. Por ejemplo Las Partidas de Alfonso X El Sabio proclamaban (Ley 3, Tít. VIII, Partida 7):

Otrosi dezimos, que si algund ome que fuesse loco, o desmemoriado, o moço que non fuesse de edad de diez años e medio, matasse a otro, que non cae porende en pena ninguna, porque non sabe, nin entiende el yero que faze.

Y el primer Código Penal español, el de 1822, en su artículo 26 afirmaba que:

Tampoco se puede tener por delincuente ni culpable al que comete la acción hallándose dormido, o en estado de demencia o delirio, o privado del uso de su razón de cualquiera otra manera independiente de su voluntad. 
Mas esto era sobre el papel. En la práctica la convivencia de enfermos mentales y presos comunes sanos era harto común. Y ello tanto fuera como dentro de España. No en vano la Exposición de motivos del Real Decreto de 1 de septiembre de 1897 se hacía eco, ya a finales del XIX, de la extraña e inoportuna convivencia de locos y sanos en los establecimientos carcelarios (Barrios, 2000).

\section{3.- LA REFORMA PENITENCIARIA.}

El pensamiento ilustrado mostraría su influencia, como no podía ser menos, en el campo penitenciario. Aunque aquí es obligado hacer una puntualización previa. La prisión, como medida sancionadora es una creación muy moderna (Von Hentig, 1968), y curiosamente marca el paso a la humanidad" de la pena (Foucault, 1978). Pero aunque esto último fuera la pretensión subyacente, lo cierto es que muy pronto se vertirían todo tipo de críticas a esta institución. De hecho, no deja de ser curioso que la llamada reforma de la prisión" es casi contemporánea a la prisión misma (Foucault, 1978). Y esta crítica, y esta desconfianza, será común en todos los países, incluida España (Dorado, 1907).

La crítica fue especialmente acentuada al comprobarse las reales condiciones de reclusión existentes en las prisiones europeas. John Howard (1726-1790), filántropo británico que se dedicó al estudio de los establecimientos hospitalarios y carcelarios de su época fue adalid del movimiento de reforma penitenciario (con ramificaciones en lo hospitalario). Fruto de esta labor serían publicaciones como The State of the Prisions in England and Wales, with Preliminary Observations and an Account of some Foreign Prisions and Hospitals (1777) y An Account of the principal lazarettos in Europe, (1791).

De sus visitas a diversos establecimientos Howard destacó la labor llevada a cabo por dos grupos de enfermeras: las Hermanas de la Caridad y las Beguinas, congregaciones que enlazaban con una tradición de asistencia enfermera a los presos, por ejemplo a cargo de los "Hermanos Obregones" ("Mínima Congregación de los Hermanos Enfermeros Pobres", que fundados por Bernardino de Obregón en el s. XVI se encargaban de la asistencia en cárceles y hospitales no propios)
(Martínez et al., 1996). Howard destaca una realidad no infrecuente en la época: la desordenada cohabitación en las prisiones de locos y sanos.

La obra de Howard, como pone de relieve Siles (Siles, 1999), tendría su continuación en las siguientes décadas. En concreto podrían destacarse los siguientes hitos:

-Elizabeth Gurney Fry (1780-1845) (Van Drenth y De Hann, 1999) fue una filántropa británica que, al igual que Howard, visita cárceles y hospitales, realizando diversos informes sobre las condiciones de vida en este tipo de establecimientos. Su visita a la prisión de Newgate en Londres le permite conocer las condiciones en las que se desarrollaba la reclusión de mujeres y niños. Conmovida, creó la Maternal Society en Brighton que iniciaría su labor de ayuda a los recluidos en 1816, concretamente mediante la inauguración de una escuela para los hijos de las reclusas. Sus posteriores visitas a las prisiones de Glasgow, Nottingham, Scheffield, Leeds, York y Liverpool confirmaron que también en estos establecimientos las prisiones padecían pésimas condiciones de reclusión.

Un año después, en abril de 1817 fundó la Ladies' Association for the Reformation of the Female Prisoners en Newgate, y posteriormente en 1821 la British Ladies' Society for Promoting the Reformation of Female Prisoners. Luego se dedicaría a visitar diversos establecimientos penitenciarios europeos.

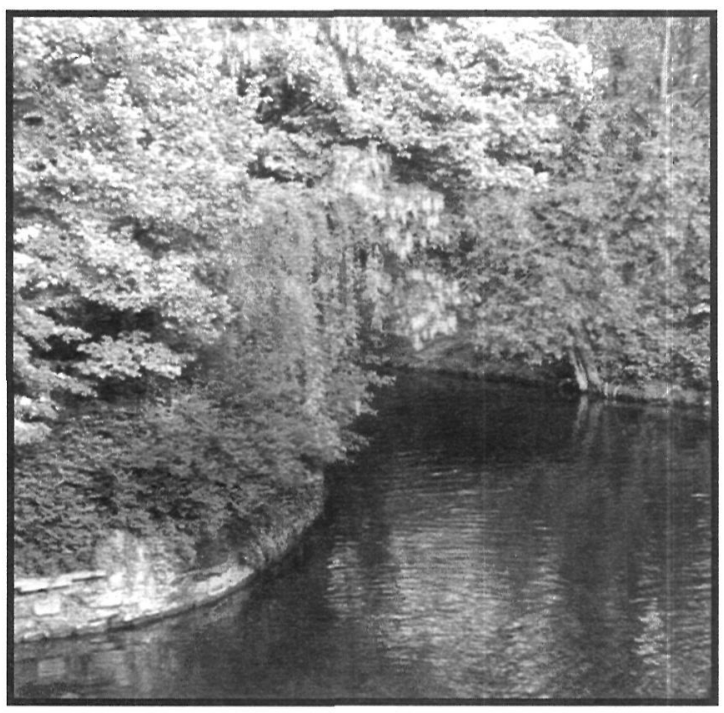


El discurso de esta reformadora hablaba de un mejor trato a los presos, de tolerancia religiosa y de la abolición de la esclavitud. En 1827 escribió Observations on the Visiting, Superintendence, and Government, of Female Prisoners en el que narra sus experiencias en la prisión de Newgate. Junto a su hermano Joseph Gurney (1788-1847) escribió Prisons in Scotland and the North of England. Joseph, gracias a su empatía con Sir Robert Peel, Secretario de Interior, lograría la introducción de algunas mejoras en el régimen penitenciario (Goals Act, 1823). Influenciada, sin duda, por los elogios que hiciera John Howard a la labor desarrollada por las Hermanas de la Caridad, fundó la Sociedad de Hermanas Protestantes de la Caridad, en 1840 que posteriormente pasaría a denominarse Instituto de Hermanas Enfermeras, especializas básicamente en las visitas domiciliarias.

- Por su parte Dorothea Lynde Dix (1802-1887) (Viney y Bartsch, 1984; Schlaifer y Freeman, 1991 y Gollaher, 1995) fue inicialmente profesora (fundó algunos internados de señoritas). Posteriormente se dedicaría a su labor filantrópica.

Se convierte en asidua visitante de la prisión de Massachussetts, a lo largo de 1841, en donde comprueba las pésimas condiciones de tratamiento y reclusión en las que se encuentran los enfermos mentales, encarcelados junto a criminales sin que existiera criterios de clasificación interior, por sexo o edad. Comprobará en los dos años siguientes que tales condiciones no eran infrecuentes en el resto de los establecimientos del Estado y por ello elabora en 1843 un informe a la Asamblea Legislativa estatal describiendo sus hallazgos. Su labor permitirá la ampliación del Worcester Insane Asylum.

Posteriormente Dix visitaría Rhode Island y New York. Su influencia es notoria en las décadas siguientes influyendo sobre la legislación de 15 estados en Estados Unidos y en Canadá. Hasta 32 instituciones serán erigidas en EE.UU. siguiendo las recomendaciones de Dorothea L. Dix. Durante su estancia en Italia en 1854-1856 transmitiría sus observaciones al Papa Pío IX. En 1845 Dix publicó Remarks on Prisons and Prison Discipline in the United States abogando por las reformas en el tratamiento de los presos. En 1861 sería nombrada Superintendente del cuerpo de enfermeras, durante la guerra civil. Tras la guerra regresaría a su labor hospitalaria.

Dorothea L. Dix falleció el 17 de julio de 1887 en el Hospital de Trenton (New Jersey) por ella fundado años antes.

- Es destacable asimismo la labor de las llamadas Diaconisas de Kaiserswerht" (Kaiserswerther Diakonissenmutterhaus), fundadas por el clérigo protestante Teodoro Fliedner (1800-1864) en 1836 en la localidad de Kaiserswerth, de donde les viene el nombre.

T. Fliedner pretendió solventar las pésimas condiciones de vida de los presos. Viajó a Inglaterra sirviéndole de inspiración la obra de Howard y la labor de Elizabeth Gurney Fry. A su vez la obra de Fliedner influiría sobre Florencia Nightingale. El movimiento de diaconisas" se extendería por todo el mundo. El propio T. Fliedner junto con cuatro diaconisas fundaría una Casa Madre en Pittsburgh en 1849, en Jerusalem en 1851, y luego se crearían otros establecimientos en París, Berlín y en otros lugares. Este movimiento fue importado por William A. Passavant (18211894) a Estados Unidos, en donde creó misiones, hospitales, orfanatos, colegios y seminarios. Al morir el 4 de octubre de 1864, 30 establecimientos (tipo Casa Madre) y 1600 diaconisas existían a lo largo del mundo. A mediados del siglo se llegaría a la cifra de 35.000 diaconisas que llevaban a cabo

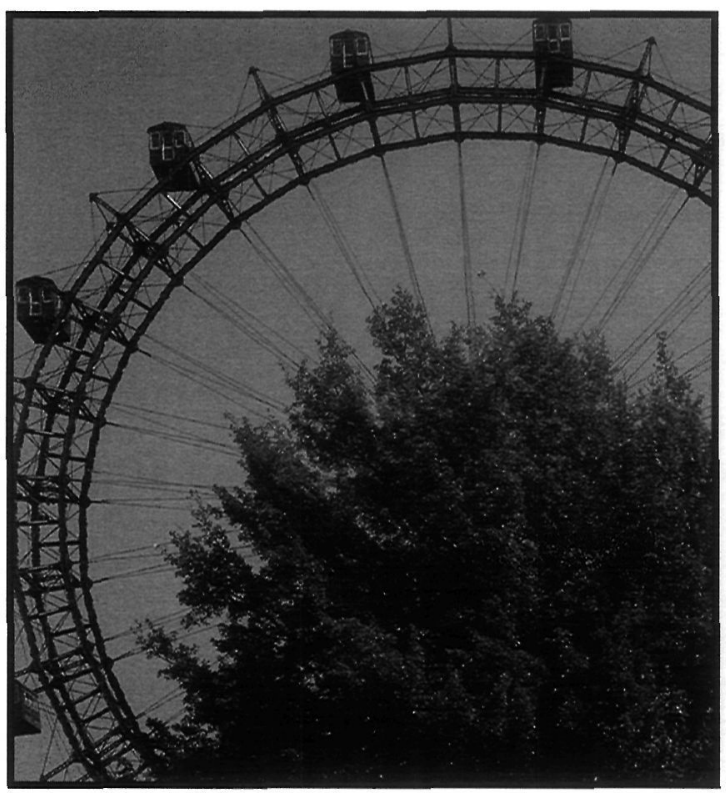


sus labores en hospitales, cárceles, parroquias y escuelas.

Queda patente, a la vista de lo expuesto, la estrecha ligazón entre labor enfermera y práctica penitenciaria. Y otro tanto sucedería en España en la figura de Concepción Arenal. La reforma de esta queda imbuida por el espíritu de reforma y mejora de la aquella, en algunos de sus más egregios representantes. Pero aún queda por ver un episodio especialmente significativo. En este caso de la historia manicomial.

\section{4.- LA REFORMA PSIQUIÁTRICA.}

Es harto conocido el gesto de Philippe Pinel (1745-1826) liberando de las cadenas a los locos de Bicêtre (Foucault, 1976). Sin menoscabar la valía del personaje es de justicia hacer algunas precisiones.

- En primer lugar, se hace precisa una puntualización histórica. Pinel aparece en la historia de la psiquiatría como punto de referencia de la reforma psiquiátrica. Se indica como punto de arranque de esta reforma un momento político que la hiciera posible (la Revolución Francesa). Y, sin embargo, eso no es del todo cierto. Antes de Pinel existen unos poco conocidos personajes que analizaron la realidad asistencial y elevaron las correspondientes propuestas de reforma. Me refiero a Jean Colombier (1736-1789) y François Doublet (17511795). Ambos fueron nombrados por Jacques Necker (1732-1804), primer ministro de Francia como Inspector General e Inspector Adjunto, respectivamente, de los Hospitales civiles y de las Prisiones. Como siempre la correlación sanitariopenitenciaria. En el ejercicio del cometido asignado elaboraron, en 1785, unas Instrucciones para gobernar a los insensatos (Colombier y Doublet, 2000). Instrucciones en las que cabe distinguir tres contenidos fundamentales. En primer lugar, un reconocimiento del derecho de los pacientes a ser asistidos ("la sociedad debe proteger de forma manifiesta y con las mayores atenciones a los seres más débiles e infelices") y una denuncia de la falta de infraestructuras asistenciales ("Disponemos en el reino únicamente de cuatro o cinco lugares preparados para tratar a los insensatos; y si prestamos atención a éstos, observaremos que tales establecimientos, a excepción de uno, carecen de los ele- mentos necesarios para tratarlos o están muy mal ubicados para que sean eficaces"). En segundo lugar un conjunto de pautas relativas a la "manera de internar, guardar y dirigir a los insensatos", que corre a cargo de Jean Colombier, cirujano mayor del ejército. Y, en tercer lugar, un elenco de terapias que se engloban bajo el título de "tratamiento de los insensatos", y que estuvo encomendada a François Doublet, especialista en enfermedades venéreas y Catedrático de medicina interna. Tras el diagnóstico del estado asistencial, el cuerpo del informe versa, por tanto, sobre el "tratamiento" y el "trato".

En lo que al tratamiento respecta, obviamente hemos de situarnos históricamente y entender" que las terapias propuestas se encuentran al nivel del conocimiento científico de la época. Por ello no ha de extrañar que: 1) Frente al frenesí se empleen: a) Abundantes sangrías, b) Bebidas abundantes, c) Lavativas (una purgante y otra emoliente) entre sangrías, d) Rapar la cabeza y colocar el bonete de Hipócrates mojado con agua y vinagre frío, e) Baños tibios seguidos de duchas frías; 2) Para la manía se aconsejan: a) Sangrías, b) Purgantes, que deberán estar precedidos de bebidas ligeras y licuadas y que tendrán carácter gradual, c) Baños tibios y duchas, d) Cauterios, sedales y úlceras artificiales e incluso inoculación de la sarna; 3) Para la melancolía conviene "sangrar con audacia" pero no continuando con purgantes; se emplearán tisanas ligeras, suero, crémor tártaro, baños tibios; después, jugos herbáceos, bolos jabonosos, píldoras hechas con goma amoniacal, cremor tártaro y mercurio dulce; finalmente, se puede purgar. Como último recurso pueden utilizarse la ducha, el sedal y otros remedios utilizados contra la manía, y 4) En los casos de imbecilidad, la terapia consistirá en buenas comidas, aguas termales, purgas con raíz de nueza y la jalapa impregnada en aguardiente y baños fríos y duchas. En caso de rechazo al tratamiento anterior pueden ser tratados como los maníacos por inanición y además se les podrán aplicar descargas eléctricas. Existen además tratamientos específicos: así para la imbecilidad provocada por la masturbación se emplearán analépticos, tónicos, aguas termales, fricciones secas e incluso la electricidad; si la causa de la imbecilidad fuera un virus podrá inocularse la sarna; si la imbecilidad 
fuera consecuencia de la apoplejía se utilizarán cauterios, aguas termales y purgantes drásticos.

En lo relativo al régimen y trato Colombier y Doublet propugnan: 1) La separación según tipología de locos: "no podemos permitirnos que existan las mismas salas para los diversos tipos de locos", por lo que "existirá un primer departamento o sección para los imbéciles, un segundo para los locos violentos, un tercero para los locos tranquilos y un cuarto para aquellos que mantengan intervalos lúcidos de cierta duración con posibilidad de curación", 2) El respeto a unas condiciones de salubridad: "es esencial que se respire en estos lugares un aire puro y que el agua sea salubre", "los paseos les proporcionarán la satisfacción y la libertad de respirar aire libre", "deben mantener la mayor limpieza en los dormitorios, en los patios, en los edificios, en la letrinas y en las ropas", "en invierno, los dormitorios de los insensatos se calentarán mientras éstos permanezcan en ellos", 3) La instauración de unas condiciones arquitectónicas pormenorizadas: un patio para cada sección, cama fija con jergón y manta, letrinas en cada celda, bañeras con agua fría y caliente, 4) Una buena alimentación. Aspecto fundamental ya que "se conoce desde tiempo atrás como la alimentación influye sobre lo moral". Incluirá: carne dos veces por semana, verduras cocidas con agua y mantequilla, libra y media de pan al día, bebida consistente en una decocción de cebada edulcorada con regaliz y acidulada con cremor tártaro y excepcionalmente vino, pero nunca aguardiente, 5) Un adecuado vestuario. Detallándose el lote de prendas a entregar a cada enfermo ("conviene que estos desgraciados estén muy pulcramente vestidos"), 6) Personal apropiado. "Es preciso que los guardias y los sirvientes destinados a las salas de enfermos en tratamiento sean vigilantes, sabios, dulces y firmes" y un 7) Régimen horario. "Debe existir una regla que fije las horas para el baño, para la distribución de los alimentos y de los medicamentos, para la apertura y cierre de las habitaciones, para los cambios de ropa y de sábanas".

Colombier y Doublet, por tanto, son inequívoca muestra de que la reforma psiquiátrica precedía a Pinel. Era reflejo de la Ilustración con anterioridad incluso al estallido revolucionario.

- En segundo lugar, es menester reclamar una atención nacional. Tradicionalmente se ha erigido Francia en sede del movimiento de reforma psiquiátrica. Y sin embargo este dato es asimismo puntualizable. Por un lado, porque ya en Inglaterra encontramos interesantes experiencias que ponen de relieve la inexactitud del dato anterior (Foucault, 1976). No puede olvidarse que en 1792 -Pinel se hace cargo de sus funciones el 25 de agosto de 1793- se establece el York Retreat, cuyo autor, William Tuke (1732-1822) publicaría en 1813 su descripción y forma de funcionamiento, el cual -básicamente- consistía en "quitar las cadenas" y dar mejor trato a los alienados.

Pero es que, además, conviene traer a colación un dato en modo alguno desdeñable. Pinel se reconoce deudor de la tradición hispana. En efecto, no es en absoluto intrascendente la influencia de la experiencia asistencial española, concretamente de la información sobre el Hospital de Zaragoza en Pinel. Lo cierto es que José Iberti, a instancias del "Comité de Mendicidad" de París emitió un informe que lleva por título Detalles sobre el Hospital de Zaragoza, en España, destinado especialmente al tratamiento de locos o maníacos, por M. Iberti, Doctor en Medicina, sería publicado en París en 1791 y fue obviamente conocido por Pinel (Espinosa, 1964) que incluso explícitamente lo afirma en su obra ("La España nos da un exemplo tan digno de imitar") (Pinel, 1804). La cuestión no es baladí, ya que por muy conocida que sea la gesta de Pinel liberando de las cadenas, no faltan autores que precisamente pongan de manifiesto que "los locos de Zaragoza nunca tuvieron cadenas" (Royo, 1935-1936).

- En tercer lugar, y es el aspecto que ha de merecernos particular atención, es pertinente una reivindicación profesional. El facultativo Pinel ha acaparado para sí toda la atención histórica -fue llamado "Washington de los locos", (Giné i Partagás, 1882)-, cuando de la transformación de la psiquiatría se trataba y, sin embargo, otro personaje -como tantas veces sucede- ha visto oscurecido su protagonismo. Me refiero, más que a un personaje a un matrimonio. Pinel en persona reconoce el decisivo papel de esta pareja, el Conseje de Bicêtre y su mujer -el especial talante y condiciones en la forma en que la mujer de M. Pussin trata a los dementes del manicomio son expresivos- en 
su obra Traité Médico-philosophique sur l'aliénation mentale (1801) (Pinel, 1804).

En efecto, ninguna duda cabe albergar de que M. Pussin, el conserje de Bicêtre (el cual incluso elaboró un opúsculo manuscrito, según constata el propio Pinel) inspiró el modelo terapéutico de Philippe Pinel: "el conserge del hospicio tenia con ellos el cuidado de un padre, era sugeto de conocimientos, y estos los habia adquirido por una larga experiencia, y por su talento y reflexîon; se aplicaba continuamente á los principios de la mas pura filantropía, cuidaba diligentemente y con tino, de que los alimentos estuviesen bien condimentados, y de evitar á los locos todo motivo de descontento y queja, era severo con los sirvientes, á fin de que estos se contuviesen, y de este modo precavia todo mal tratamiento, y todo acto de violencia, usaba prudentemente de medios de bondad, y en ocasiones de una entereza inflexîble para hacerse respetar y temer de los locos, ó sujetar en ciertos casos su ciega y arrebatada fogosidad: en una palabra, poseia los primeros principios del arte de gobernarlos, principios que era necesario hacer mas fecundos y extensos,... tuvimos largas conversaciones, en las que nos instruiamos ámbos,... he aquí los materiales que me sirven en la actualidad de base para la curación moral"

$\mathrm{Y}$ en otro momento de su obra Pinel describe como -siguiendo el ejemplo del conserje- ha de tratarse a los pacientes: "Poco se puede adelantar en los medios morales, útiles para curar la manía, ateniéndose á las máxîmas generales que ya conocieron los antiguos sobre el arte de consolar á los locos, hablarlos con benevolencia, darlos unas veces respuestas evasivas para no irritarlos, si se les niega lo que piden, otras inspirarlos un temor saludable, y triunfar de su obstinación inflexîble sin violentarlos. Estas son, por decirlo así, verdades estériles, si no determinamos con exâctas observaciones las circunstancias del lugar, tiempo y carácter del loco, naturaleza particular de sus extravíos, y lesiones variadas de las facultades morales, y si no fixamos de este modo la juiciosa aplicación de los preceptos generales, refiriendo con igual candor los casos del bueno, como del mal éxîto de este método; porque ¿á qué fin no hemos de confesar que en el estado actual de nuestros conocimientos hay dificultades que todavía no han podido vencerse?".

El ejemplo que le sirve a Pinel de inspiración M. Pussin- está más que probado. Pinel postula -en la línea antecesora de M. Pussin- por: a) cuidar de la alimentación de los pacientes ("Cuidado paternal que se ha de tener en el modo de guisar y distribuir los alimentos á los locos"), b) un criterio clasificatorio (y así por ejemplo considerará "muy importante separar en los hospitales de locos la numerosa especie que forman los idiotas", c) humanidad en el trato (pues "es preciso hacerse temer del loco; pero no se debe practicar con él ningún acto de violencia"), d) un personal cualificado para el trato con los pacientes ("Sutileza, zelo ardiente, y una atencion continuada ó infatigable, he aquí las qualidades necesarias para espiar con cuidado e modo de obrar de cada loco, y conocer sus extravagantes designios, y el carácter particular de su delirio;...").

\section{5.- EL PANÓPTICO COMO PROPUESTA DE "DOBLE USO".}

Jeremías Bentham (1748-1832), describe en su el sistema Panóptico, sistema que en principio está pensado para los presos, de ahí su subtítulo:

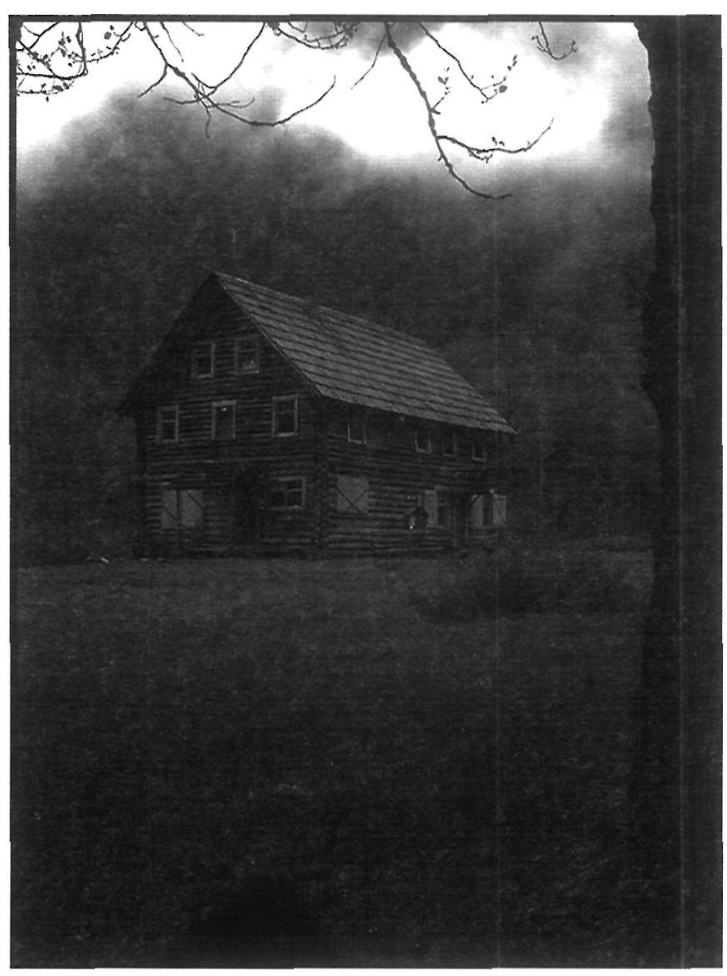


"Establecimiento propuesto para guardar los presos con mal seguridad y economia, y para trabajar al mismo tiempo en su reforma moral, con medios nuevos de asegurarse de su buena conducta, y de proveer a su subsistencia despues de su soltura". Aunque lo cierto es que el propio Bentham reconoce su posible aplicación a otro tipo de "inquilinos": "los gobiernos podrían aplicar a diferentes objetos de la mayor importancia", ya que "para hacer la aplicación sucesiva del mismo principio a todos los otros establecimientos, no habría mas que hacer que despojar a este de algunas de las precauciones que exige", por lo que "el principio panóptico puede adoptarse con feliz éxito á todos los establecimientos en que se deban reunir la inspección y la economía".

Lo característico del Panóptico es el sistema de inspección: "La inspección: este es el principio único para establecer el orden y para conservarle; pero una inspección de un nuevo género, que obra mas sobre la imaginación que sobre los sentidos, y que pone á centenares de hombres en la dependencia de uno solo, dando á este hombre solo una especie de presencia universal en el recinto de su dominio". Y todo ello en un sistema de dulzura, severidad y economía.

Sin embargo, tras la apariencia de modernismo se esconde una trampa que descubre Foucault en

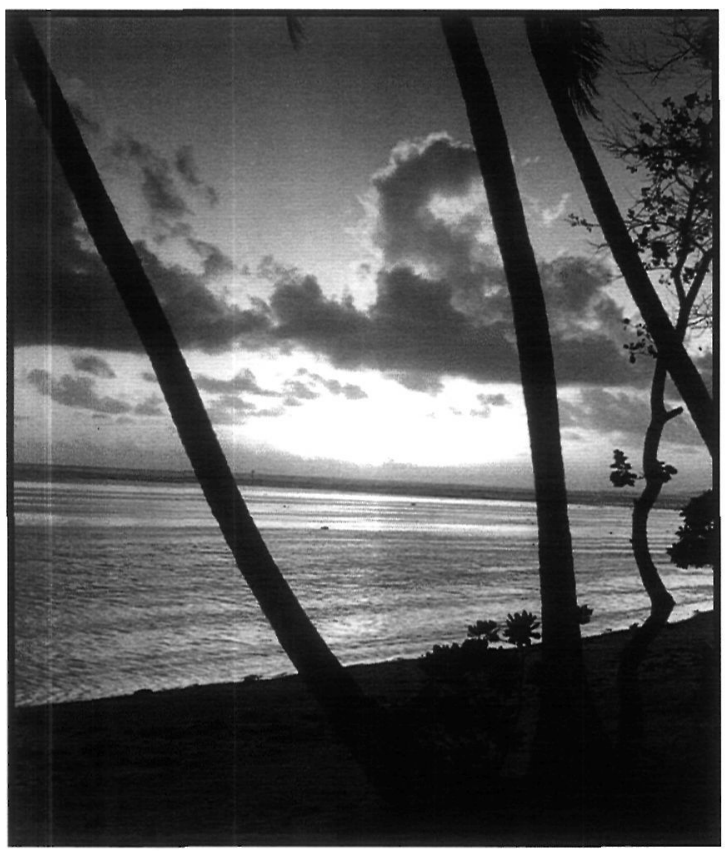

los siguientes términos: "se invierte el principio del calabozo; o más bien de sus tres funciones encerrar, privar de luz y ocultar-; no se conserva más que la primera y se suprimen las otras dos. La plena luz y la mirada de un vigilante captan mejor que la sombra, que en último término protegía. La visibilidad es un trampa" (Foucault, 1979). El panóptico es la inversión del modelo arquitectónico clásico -arquitectura del espectáculo- para convertirse en una arquitectura de la vigilancia. Mas, en cualquier caso, "el panoptismo se opone a la teoría legalista [de Beccaria]" (Foucault, 1995).

En definitiva, el Panóptico es un elemento de propuesta de intervención característico de la época: técnico -acompañado de una abundante descripción de sus elementos materiales- y polivalente -para el uso carcelario y hospitalario-. El "doble uso" -manicomial-carcelario- viene a constatar una trayectoria histórica común de los "establecimientos de humanidad".

\section{6.- LA LUCHA POR LA DIFERENCIACIÓN.}

Aunque el fundamento teórico de origen y las propuestas prácticas de intervención fueran comunes, desde comienzos del XIX se aprecia lo inadecuado de la confusión cárcel-manicomio (aunque en buena medida tal inadecuación obedeciera a razones utilitarias). Al mismo tiempo la profesión de enfermero demandó una identidad propia. Nos encontramos así con un doble movimiento de diferenciación-identificación:

- Por un lado, se reclamará la creación de establecimientos propios para los enfermos delincuentes. La prisión no es de recibo para albergar a este tipo de personas -era un anacronismo que convivieran locos y sanos, pero también era un atentado a los principios clasificatorios tan caros a esta época-. El manicomio podría ser insuficiente (habida cuenta del tipo de enfermos al que nos estamos refiriendo). En algunos países europeos la opción fue clara: de modo temprano se erigieron establecimientos psiquiátricos penitenciarios en Broadmow (Inglaterra), Perth (Escocia), Dundrum (Irlanda), Bicêtre (Francia) y Bruges (Bélgica); en España, la respuesta fue mucho más tardía (Barrios, 2000).

- Por otro, la enfermería reclamará su papel e identidad propia. El movimiento reformista en el 
que se integran Howard, Elizabeth Gurney Fry, Dorothea Lynde Dix y las diaconisas de Kaisersweth (Siles, 1999) sentará en parte las bases de esa consolidación profesional. Aunque junto a él es de inevitable cita la ingente labor práctica y docente de Florence Nightingale (18201910 ), quien junto a su valiosa experiencia en la guerra de Crimea (1854-1855) une una importante labor en la creación de los estudios de enfermería.

Y como inevitable síntesis de ambos fenómenos se hará preciso reconocer la dotación de cuidados enfermeros a la población alienada penitenciaria. En este sentido, y refiriéndome exclusivamente al caso español hay que partir de un estado crónicamente deficiente de la sanidad penitenciaria. Ejemplo de ello es que, a pesar de las disposiciones de la Ordenanza General de Presidios de 1834, ordenando la creación de enfermerías (art. 149), lo cierto es que las mismas fueron con frecuencia incumplidas (Llorca, 1992). Y en los lugares en que existía enfermería rara vez esta se ajustaba a las prescripciones higiénicas, aunque "relativamente a las otras dependencias presidiales, la enfermería es la que reune condiciones menos malas" (Cadalso, 1893). Y si lo anterior es predicable de las dependencias, qué decir del personal. La dotación de enfermeros auxiliares (hasta la muy reciente incorporación de celadores y auxiliares de enfermería) se llevaba a cabo mediante concurso entre funcionarios (Oficiales y Guardianes, en términos de la época) (art. 13 Decreto 5.7.1933 Decreto que preveía incluso la existencia de una Escuela de Enfermeros Psiquiátricos, bajo la dirección del Médico-Director del Hospital Psiquiátrico Judicial de Alcalá de Henares, tradición hace tiempo desaparecida- o el art. 123 del Reglamento de Servicios de Prisiones de 1948.

\section{7.- CONCLUSIONES.}

A la vista de la exposición precedente podrían llegarse a las siguientes conclusiones:

1.- La transformación de la custodia (régimen penitenciario y psiquiátrico) y cuidados (régimen hospitalario y penitenciario) acontece en un momento histórico coetáneo aunque dilatado en el tiempo, la Ilustración.

2.- Es recurrente la relación existente entre las experiencias sanitarias (manicomiales incluidas) y carcelarias. Y ello tanto en el plano de la construcción teórica (el caso de Bentham es ilustrativo) como en el de la intervención práctica (propuestas de los adalides de la reforma sanitario-penitenciaria).

3.- A lo largo del XIX se demanda una distinción (especialización) entre ambas prácticas. Y como consecuencia de ello se reclaman instituciones diferenciadas e, incluso, personal con características propias. En España la respuesta siempre llegó tarde.

\section{BIBLIOGRAFÍA}

- Barrios, LF (2000). Un siglo de psiquiatría penitenciaria. Revista de la Asociación Española de Sanidad Penitenciaria, 1, 23-30.

- Bentham, J. (1822). Tratados de legislación civil y penal, obra extractada de los manuscritos del señor Jeremías Bentham, jurisconsulto inglés, por Esteban Dumont, miembro del Consejo Representativo de Ginebra y traducida al castellano, con comentarios por Ramón Salas, ciudadano español, y doctor de Salamanca, con arreglo a la segunda edición revisada, corregida y aumentada, V. Madrid, Imprenta de D. Fermín Villalpando.

- Berlin, I. (1998). Cuatro ensayos sobre la libertad. Madrid, Alianza Editorial.

Bernaldo de Quirós, C. (1908). Las nuevas teorías de la criminalidad. Madrid, Imprenta de la Revista de Legislación.

- Cadalso, F. (1893). Estudios Penitenciarios. Presidios Españoles, escuelas clásica y positiva y colonias penales. Madrid, Centro Edit. de F. Góngora.

- Carasa, P. (1988). Crisis del Antiguo régimen y Acción Social en Castilla. Madrid, Junta de Castilla y León.

- Colombier, J. y Doublet, F.(2000): Instrucciones para gobernar a los insensatos y para trabajar en su curación en los asilos que les son destinados. Revista de la Asociación Española de Neuropsiquiatría XX (73), 71-88.

- Comelles, J.M. (1988). La razón y la sinrazón. Asistencia psiquiátrica y desarrollo del Estado en la España contemporánea. Barcelona, PPU.

- Dorado, P. (1907?). El Derecho protector de los criminales, s.1., s.i., s.n. [1907?]. [He manejado una prueba incompleta de su obra en su propia biblioteca personal en la Univ. Salamanca, Casa Miguel de Unamuno].

- Espinosa, J. (1964). Un testimonio de la influencia de la psiquiatría española de la ilustración en la obra de Pinel: el informe de José Iberti acerca de la asistencia en el Manicomio de Zaragoza (1791). Asclepio XVI.

- Foucault, M. (1976). Historia de la locura en la época clásica, II. Madrid, Fondo de Cultura Económica. 
- Foucault, M. (1978). Vigilar y castigar. Madrid, Siglo XXI.

- Foucault, M. (1979). El ojo del poder. En: Bentham, J. El panóptico. Madrid, La Piqueta.

- Foucault, M. (1995). La verdad y las formas jurídicas. Barcelona, GEDISA.

- Foucault, M. (1999): )Qué es la Ilustración?. En: Estética, ética y hermenéutica, Barcelona, Paidós.

- García, A. M., García, M. y Valle, J.I. (1996). Un siglo de oro para la enfermería española (1550-1650): I. Aparición de órdenes y manuales de enfermería. En Hernández, F. (Coord.). Historia de la Enfermería en España (Desde la antigüedad hasta nuestros días). Madrid, Síntesis.

- Giné i Partagás, J. (1882). Curso elemental de higiene privada y pública, II. Barcelona, Librería de Juan y Antonio Bastinos Edits.

- Gollaher, D. (1995). Voice for the Mad: The Life of Dorothea Dix. Toronto, The Free Press.

- Hirschberger, J. (1976). Historia de la Filosofía. Barcelona, Herder. II: 145-160.

Kant, I. (1990). Respuesta a la pregunta: ¿Qué es Ilustración?. Valencia, Universidad de Valencia. [Original, 1783].

- Lardizábal, M. (1782). Discurso sobre las penas contrahido a las leyes criminales de España para facilitar su reforma. Madrid, Joaquín Ibarra, Imp.

- Llorca, J. (1992). Cárceles, presidios y casas de corrección en la Valencia del XIX (Apuntes históricos sobre la vida penitenciaria valenciana). Valencia, Tirant lo Blanch. Marco, F. (1950). Vida y obra del P. Jofré. Archivos Iberoamericanos de Historia de la Medicina, II (2).

- Miranda, M0 J. (1979). Bentham en España. En Bentham, J. El panóptico, Madrid, La Piqueta, 127-145. - Pinel, F. (1804): Tratado médico-filosófico de la enagenación del alma, o manía. Madrid, Imprenta Real.

- Royo, J.M. (1935-1936). El Manicomio de Zaragoza (Seis siglos de fundación). Trabajos de la Cátedra de Historia Crítica de la Medicina, VII.

- Schlaifer, Ch. y Freeman, L. (1991). Heart's Work: Civil War Heroine and Champion of the Mentally Ill, Dorothea Lynde Dix. New York, Paragon House.

- Siles, J. (1999). Historia de la enfermería. Alicante, Aguaclara.

- Tomás y Valiente, F. (1974): Introducción. En Beccaria, C. De los delitos y de las penas. Madrid, Aguilar.

- Van Drenth, A. y De Haan, F. (1999). The Rise of Caring Power : Elizabeth Fry and Josephine Butler in Britain and the Netherlands, Amsterdam, Amsterdam Univ. Press.

- Viney, W. y Bartsch, K. (1984). Dorothea Lynde Dix: Positive or negative influence on the development of treatment for the mentally ill. Social Science Journal 21 (2), 71-82.

- Von Hentig, H. (1968). La Pena, II. Las formas modernas de aparición. Madrid, Espasa-Calpe. 